\title{
PERCEPÇÕES DA CRIANÇA ACERCA DO CUIDADO RECEBIDO DURANTE A HOSPITALIZAÇÃO' 1
}

\author{
CHILDREN'S PERCEPTION REGARDING THE CARE RECEIVED DURING \\ HOSPITALIZATION \\ PERCEPCIONES DEL NIÑO SOBRE EL CUIDADO RECIBIDO DURANTE \\ LA HOSPITALIZACIÓN
}

\author{
Cláudia da Costa Silva ${ }^{2}$ \\ Nair Regina Ritter Ribeiro ${ }^{3}$
}

\begin{abstract}
RESUMO - Estudo qualitativo exploratório realizado num hospital escola de Porto Alegre, objetivando identificar percepções das crianças acerca do cuidado durante a hospitalização. Participaram oito crianças, de seis a doze anos. A participação foi autorizada pelo responsável mediante assinatura do termo de consentimento informado. Coletou-se os dados na unidade de internação, com entrevistas focalizadas. Analisando as falas emergiram cinco temas: Identificando os Cuidadores; Percepções da Criança a Respeito do Cuidado; Sentimentos Externados; Caracterizando o Cuidado e os Cuidadores; Percepções Acerca do Tempo. Evidenciou-se que a hospitalização gera stress para a criança e sua família. Um cuidado adequado, humanizado e eficiente minimiza o impacto da hospitalização. Nele estão inseridos: engajamento da família e da criança no cuidado, manutenção do vínculo familiar e das suas atividades normais, explicação prévia dos procedimentos a serem realizados, valorização das opiniões e sugestões da criança, disponibilidade e atenção da equipe as suas necessidades.
\end{abstract}

PALAVRAS-CHAVE: cuidado, hospitalização infantil, percepções da criança

\section{INTRODUÇÃO}

No decorrer do Curso de Graduação em Enfermagem, sempre procurei experiências que me oportunizassem uma maior convivência com o universo infantil. Foi com este olhar voltado para a Enfermagem Pediátrica, que pude constatar que a maior parte dos trabalhos realizados nesta área, bem como a prática diária nas unidades de internação pediátrica, estão direcionadas para as peculiaridades anatomo-fisiológicas do cliente pediátrico, as fases do desenvolvimento infantil e o conhecimento dos pais em relação à criança, no que diz respeito ao seu bem estar, suas necessidades e sua forma de expressar-se.

Sem dúvida, a especialização é cada vez mais uma qualidade requisitada a todo o profissional. Dentro da Enfermagem Pediátrica este fator assume papel chave, diante das rápidas mudanças de estado as quais as crianças estão sujeitas, sobretudo no seu primeiro ano de vida. Este fato deve-se à fragilidade de seus sistemas orgânicos frente a desorganizações próprias ou impostas pelo meio.

O reconhecimento das fases do desenvolvimento infantil é o fator primordial para o cuidado adequado a estes clientes, acrescido das habilidades técnicas adquiridas e do conhecimento

1 Trabalho de conclusão do Curso de Graduação em Enfermagem da Universidade Federal do Rio Grande do Sul.

${ }^{2}$ Acadêmica de Enfermagem - EEUFRGS.

3 Profa. Dra em Enfermagem da EEUFRGS e Curso de Enfermagem da UNISINOS. 
acerca da anatomia, fisiologia e todas as nuanças que envolvem o atendimento à criança. $A$ união destes fatores possibilita intervenções rápidas e eficientes por parte da equipe de enfermagem.

Para Wong (1999, p.74), " o crescimento e o desenvolvimento, usualmente referidos como unidade, expressam o somatório de numerosas alterações que ocorrem durante a vida de um indivíduo". A mesma autora salienta ainda a importância das enfermeiras reconhecerem os problemas de saúde característicos a cada fase do desenvolvimento, muitos dos quais podem inclusive determinar a necessidade de hospitalização.

Um cuidado humanizado por parte da equipe multiprofissional que trabalha junto à criança, sensível às suas necessidades e angústias, bem como às de sua família, contribui para diminuir o impacto da internação na vida da criança e daqueles que a cercam.

O relacionamento da equipe de saúde com a criança frequentemente ocorre através dos pais, embora as crianças sejam seres distintos. Quando avalia a criança, a enfermeira utiliza uma série de informações, verbais e não-verbais, colhidas com a própria criança ou com os pais, pois estes são, geralmente, as pessoas que mantém o maior contato com ela (Wong, 1999). Para o autor, durante seu desenvolvimento ao chegar a idade escolar (6 a 11 anos), a criança já tem domínio da linguagem e dirige sua atenção para um mundo mais amplo, fora do grupo familiar.

Porém para uma comunicação efetiva e sobretudo humanizada com o universo infantil, é necessário muito mais do que reconhecer suas formas de expressão e peculiaridades segundo faixas etárias.

Ceccim (1997), afirma que ao cuidarmos da criança devemos estar atentos aquelas coisas que importam e têm significado para ela. Precisamos compreender que brincadeiras engraçadas e explicações para os pais não são suficientes para tornarem a nossa conduta adequada às necessidades infantis (Carvalho, 1997).

A criança não é um adulto em miniatura e nem tão pouco é menos importante ou deve ter suas opiniões menos respeitadas, por ser menor em tamanho ou por não compreender sequências de idéias, que formam o pensamento dos adultos. A comunicação que respeita a criança como "ser individual" que ela é e valoriza aspectos que para ela tem valor, toma proporções importantíssimas atualmente, quando os avanços tecnológicos aumentam a qualidade e a própria expectativa de vida para crianças portadoras de patologias crônicas ou de longa duração, como é o caso de pneumopatas ou hepatopatas. Na busca aos benefícios proporcionados pela medicina e tecnologia modernas, as crianças e suas familias são submetidas a inúmeras internações e expostas a todo o stress gerado pelas mesmas.

Carvalho $(1997$, p. 18) afirma que muitos profissionais vêm repensando o papel da criança no contexto da hospitalização pediátrica e reconhecendo que ela não é um simples objeto da assistência. Questiona se "estamos levando em conta o que esse paciente tenta nos dizer ou nos fazer entender - as suas ansiedades, as suas fantasias e as suas necessidades".

Acredito que a criança deve ser tratada e ouvida como um sujeito atuante, no contexto do cuidado estabelecido na hospitalização, e não como um mero objeto deste cuidado. Nesta perspectiva, este estudo partiu da questão norteadora, assim colocada:

" Quais são as percepções da criança acerca do cuidado que ela recebe durante a hospitalização? "

Decorrentes desta questão, foram elaborados os seguintes objetivos:

- Identificar a percepção da criança sobre o cuidado que recebe durante a hospitalização;

- Conhecer a percepção da criança sobre os procedimentos de enfermagem a que é submetida e qual a melhor maneira de realizá-los;

- Verificar como a criança identifica os cuidadores e como os caracteriza. 


\section{METODOLOGIA}

Tipo de Estudo - Este é um estudo exploratório descritivo com dados qualitativos. Contexto da Pesquisa - Os dados foram coletados na Unidade de Internação Pediátrica Ala Sul $\left(10^{\circ} \mathrm{sul}\right)$, de um Hospital Escola de Porto Alegre. Esta é uma das quatro unidades que compõe o Serviço de Enfermagem Pediátrica do referido hospital e foi escolhida por concentrar o maior número de crianças internadas com a faixa etária abrangida pelo estudo. De um modo geral, nesta unidade são assistidas crianças de 1 mês até 12 anos de idade, com patologias clinicas e cirúrgicas. A capacidade da unidade é de 34 leitos. A equipe de enfermagem é composta por 8 enfermeiras e 51 aux. de enfermagem, distribuidos em 2 turnos diurnos (manhã e tarde) de 6 horas e 3 turnos noturnos (N1, N2 e N3) de 12 horas. As enfermeiras desenvolvem atividades assistenciais, educacionais e administrativas, trabalhando no cuidado direto ao paciente $\mathrm{e}$ dando suporte à equipe de auxiliares.

Participantes do estudo - Participaram deste estudo 8 crianças, entre 6 e 12 anos, apenas uma em sua primeira internação hospitalar. São crianças não portadoras de lesão cerebral ou outra patologia que pudesse interferir em sua comunicação verbal.

A definição de um número minimo de internações ocorreu com o propósito de incluir no estudo crianças que tivessem vivenciado um maior número de relações de cuidado, desenvolvidas durante a hospitalização. A entrevista com uma criança que estava em sua primeira internação ocorreu devido a curiosidade quanto às diferenças do conteúdo de seu depoimento quando comparado aos de outras crianças, que já tivessem vivenciado esta experiência. Seu depoimento foi incluido no estudo devido a riqueza de dados, apesar de ser a primeira internação.

A limitação da idade minima foi fixada de acordo com a classificação das fases do desenvolvimento, apresentadas por Wong (1999). A autora afirma que o escolar, fase que compreende crianças de 6 a 11 anos, já emprega adequada e satisfatoriamente a linguagem. $O$ número de participantes foi definido através da saturação de dados, isto é, quando a coleta de dados pára de produzir novas informações (Polit; Hungler, 1995).

Identificando os participantes - Os nomes verdadeiros das crianças foram substituídos por nomes ficticios. Assim, participaram deste estudo:

- Aline, nove anos, portadora de Diabete Melitus (DM), quarta internação hospitalar;

- Joana, sete anos, portadora de Fibrose Cística (FC), quinta internação hospitalar;

- Luan, nove anos, internou para correção de Hipospádia, primeira internação hospitalar;

- Milena, doze anos, portadora de FC, vigésima terceira internação hospitalar;

- Nádia, dez anos, portadora de FC, oitava internação hospitalar;

- Régis, nove anos, internado para tratamento de Osteomielite, já internou antes por Otite Média Aguda (OMA) e por Broncopneumonia (BCP), totalizando três internações hospitalares;

- Vanessa, doze anos, portadora de Retrosigmoidite Ulcerativa Crônica, oitava internação hospitalar;

- Vitor, onze anos, portador de FC, segunda internação hospitalar.

Coleta de Dados - A coleta de dados ocorreu através de entrevista focalizada, realizada com a criança, em companhia ou não de um familiar. Foram utilizadas também informações contidas em um diário de campo condensado, onde foram feitos registros de observações assistemáticas, realizadas conforme surgiram as oportunidades.

As entrevistas foram gravadas e transcritas, visando a análise integral dos dados, sempre com a permissão verbal da criança e do familiar responsável, que oficializou esta permissão através da assinatura do Termo de Consentimento Informado, do qual recebeu uma cópia. As fitas utilizadas para a gravação das entrevistas, logo após sua transcrição, foram apagadas. 0 periodo de coleta de dados foi de 01 e 15 de junho de 2000.

Análise dos Dados - Os dados foram trabalhados neste estudo através da categorização 
proposta por Gomes (1999). Após a transcrição das entrevistas foi feito um levantamento das informações evidenciadas. Logo a seguir separei estas informações por categorias, segundo o assunto que focalizavam. Cada categoria enfocou um tema referente à percepção da criança em relação ao cuidado, vivenciado por ela durante a internação hospitalar. De acordo com a diversidade de idéias dentro de cada categoria, ou tema, foram criados sub-temas. Os temas foram analisados em separado, enfocando todos os sub-temas que emergiram dos depoimentos das crianças, relacionando-os à literatura.

Aspectos Éticos - A abordagem das crianças selecionadas para participarem do estudo foi realizada somente após a assinatura do consentimento informado. por parte de seus responsáveis. O documento foi redigido em duas vias, permanecendo uma delas com o responsável pela criança e a outra com a pesquisadora. Contém informações acerca dos objetivos e metodologia do estudo e assegurou ao responsável sigilo sobre a sua identidade e da criança, e a liberdade de se recusar a participar da pesquisa em qualquer de suas etapas, sem prejuizo à assistência da criança. Também Ihe foi garantido todo o esclarecimento que julgasse necessário no decorrer do estudo (Ribeiro,1995).

\section{CONHECENDO AS PERCEPÇÖES INFANTIS}

O olhar atento e afetuoso voltado aos depoimentos das crianças permitiu-me interpretar sua visão acerca do processo de cuidado, desenvolvido durante a hospitalização. Percebi, através de suas falas, as quais não serão citadas de forma integral, o surgimento de cinco temas, que enfocam suas percepções e vivências dentro do universo hospitalar.

Identificando os cuidadores - $\mathrm{O}$ ato ou ação de cuidar permeia quase todas as atividades desenvolvidas durante o processo de internação hospitalar. " O cuidado acontece nos seres, a partir deles, coexistindo na natureza e por onde suas estruturas podem ser pensadas, pois encontra-se na estrutura da organização da vida dos seres, nos seus vários domínios, biológicos, antropológicos, psicológicos, sociológicos e outros. O cuidado é um sistema que depende das interaçöes entre os individuos" (Erdmann, 1998, p. 64).

Waldow (1998, p. 134). define o processo de cuidar como "a forma como se dá o cuidado. É um processo interativo, entre cuidador e ser cuidado". A mesma autora, discutindo as idéias de Mayroff, nos diz que "o cuidador deve ser capaz de entender as necessidades do outro e de responder a elas de forma adequada". Cita também uma série de ingredientes que devem fazer parte do comportamento dos cuidadores: comportamento mais flexivel, paciência, honestidade, confiança e humildade.

A maioria das crianças em seus depoimentos identifica como cuidadores todos os componentes da equipe de saúde e muitas delas, inclusive evocando suas categorias profissionais. São citados os auxiliares de enfermagem, as enfermeiras e os médicos. Na fala das crianças, geralmente a equipe de enfermagem é colocada em primeiro plano, o que leva a crer que a referência está relacionada ao maior tempo de permanência destes profissionais junto às crianças.

Segundo Wong (1999, p. 56), "na maioria das sociedades a familia parece ter três objetivos principais em relação às crianças: cuidar, nutrir e treinar". Entretanto, em seus depoimentos, apenas uma das crianças identificou pai e mãe como cuidadores.

... um monte de gente! Enfermeiras... Algumas são médicas também... Até a minha mãe e o meu pai! (Luan, 9 anos).

Aparentemente, a chegada ao ambiente hospitalar, transfere a responsabilidade em relação ao cuidado da criança, da familia para a equipe de saúde. Este sentimento está expresso não somente nas falas das crianças, mas também fica explicito no comportamento de algumas familias, quando estas abdicam de atividades da rotina diária, como higienizar e alimentar a criança, preferindo que estes cuidados sejam realizados pela equipe de enfermagem. Cabe 
salientar que este comportamento por parte da familia não é frequente, pois a maioria realiza ou ajuda a realizar estes cuidados.

O periodo de hospitalização da criança torna-se propicio para estimular ou reforçar o vinculo familiar, uma vez que o familiar tem o tempo disponivel para a criança. Quando a familia continua realizando os cuidados relacionados às atividades do cotidiano, de certa forma está assegurando a manutenção do vínculo familiar, embora esteja em um ambiente estranho.

A presença dos pais é de fundamental importância pois, como afirma Ribeiro (1991, p. 299), "a criança, geralmente, percebe os pais como seres poderosos e busca neles apoio, ajuda, segurança, orientação e proteção".

Neste estudo, quando os cuidadores são especificados pela criança, geralmente o fazem por caracteristicas pessoais como cor de cabelo, altura, estado de gravidez, ou ainda por comportamentos demonstrados junto à criança, como por exemplo, "aquela que faz cosquinhas". No entanto em vários depoimentos há a referência aos nomes dos cuidadores e a identificação de suas categorias profissional, como enfermeiras. Constata-se que alguns destes cuidadores nominados são auxiliares de enfermagem e outros são enfermeiras, porém, todos eles estavam cuidando a criança que os citou, no turno em que a entrevista foi realizada ou no turno imediatamente anterior.

Este fato nos faz crer que as crianças possuem uma capacidade de memória restrita a um curto espaço de tempo.

Segundo Piaget, a capacidade de não restringir-se ao "atual" só é alcançada no estágio das operações formais, com inicio aproximadamente aos onze anos. (Wong. 1999)

A citação de nomes próprios de cuidadores foi observada na fala de crianças com idade inferior a onze anos. As crianças com mais idade referiram-se muito mais ao cargo ocupado pelo cuidador do que ao seu nome.

Percepções da Criança a Respeito do Cuidado - A hospitalização de uma criança implica no afastamento, do seu meio ambiente natural de convivio para uma realidade inteiramente diferente, onde as relações de cuidado desenvolvem-se sob novas óticas, que não aquelas a que a criança está habituada.

Para Motta (1988, p. 173) "a hospitalização gera uma ansiedade muito grande, refletindose na criança como um todo, e de maneira expressiva em sua percepção e compreensão". Esta situação estressante é reforçada pelos sentimentos que induz, de dor, medo e desconforto, causados pela própria doença e pelos procedimentos a que a criança é submetida.

Já antes do nascimento o individuo sente o que é cuidado ou não na relação feto-mãe. Experienciando logo a seguir o "ser criança", aprende a "receber mais diretamente os primeiros fundamentos do que é ser cuidado, do que é cuidar" (Gonzaga; Arruda, 1998, p. 196).

Em seus comentários sobre o cuidado durante a hospitalização, as crianças que participaram do estudo expressam percepçōes acerca do comportamento dos cuidadores. A maioria delas identifica a realização de procedimentos pelos profissionais como sendo atitudes de cuidado. "Entende-se por procedimento toda a ação ou tarefa necessária ao atendimento do paciente, realizada por qualquer profissional" (Ribeiro, 1991, p. 223).

Fazem o teste em mim (hemoglicoteste). Uma vê minha pressão, a outra vê minha febre, vê meu coração (Aline, 9 anos).

.. cuida da gente no quarto, escuta aqui, olha ali (Nádia, 10 anos).

Identificam também a ajuda dos cuidadores em ações realizadas na sua rotina diária, dificultadas em função de restrições impostas pela situação de doença.

Elas me ajudam em tudo. Me ajudam quando eu preciso ir ao banheiro. Quando eu preciso de alguma coisa (Régis, 9 anos).

As crianças demonstram também um sentimento de valorização dos esforços do cuidador em relação ao seu bem-estar. O fato de realizar com cuidado e de forma lenta, um curativo ou um procedimento, ou ainda o fato de adaptarem os horários de medicação para que a criança 
não fique restrita ao quarto, é valorizado por elas.

Quando ela vai tirar o último paninho (curativo), que tá bem grudado, ela coloca um monte daquela aguinha (soro fisiológico) gelada (Régis, 9 anos).

Ela brinca mais comigo! Ela faz o teste bem devagarinho (Aline, 9 anos).

As medicações também. Eles sempre ajeitam os horários prá mim poder sair! (Milena, 9 anos)

As crianças valorizam e reconhecem no comportamento do cuidador a intenção de compartilhar as ações de cuidado com a própria criança e sua família.

Elas ouvem a gente também. Ouvem a minha opinião, da minha mãe, e acho que dos outros pacientes também! (Vanessa, 12 anos).

Ela diz prá mim chorar de vez em quando. Prá mim não chorar bastante senão estoura a veia (Joana, 7 anos).

As crianças tendem a reprimir as manifestações de dor, Ribeiro (1991, p. 220) afirma que elas "têm necessidade de saber que é permitido expressar sua dor. Saber que podem gritar, chorar ou gemer faz com que manifestem seus sentimentos em uma atmosfera de apoio e aceitação".

No depoimento a seguir, a criança demonstra-nos claramente sua percepção aguçada em relação ao universo que a cerca:

Tem umas que chegam brincando, já rindo. Tem umas que são meio sérias, já é mais por fazer o remédio e tá pronto, deu! Outras não. Já tem o prazer de fazer aquele remédio, de estar ali fazendo as coisas prá mim! Prá mim melhorar! (Milena, 12 anos).

A criança percebe e valoriza o cuidado afetuoso e carinhoso prestado pelos cuidadores. Este cuidado, somado ao cuidado técnico, complementa-o, significando uma fonte de bemestar durante o período de reabilitação e recuperação das funções em desequilibrio, bem como uma melhor qualidade de vida à criança e a seus familiares (Gonzaga; Arruda, 1998, p. 204).

Por outro lado, percebem também nas ações dos cuidadores momentos de intransigência em relação à atuação da criança como agente do próprio cuidado. anos).

Digo! Alguns não aceitam. Acham que tem que ser como eles querem (Milena, 12

Entretanto, as crianças demonstram em muitas ocasiões emitirem opiniões e sugestões, direcionando as ações dos cuidadores, na tentativa de alcançarem o máximo de bem-estar possivel.

Eu falo, dai elas fazem devagar, do jeito que eu gosto (Régis, 9 anos).

Apresentam inclusive comportamentos que evidenciam ações de auto-cuidado, sem a interferência dos cuidadores, como por exemplo quando verificam o estado da fixação de curativos e dispositivos de infusão intravenosa

... mexo na veia prá ver se tá frouxo, e às vezes tá. Isso eu não gosto (Joana, 7 anos).

É esperado que a criança passe a participar do seu cuidado, a medida em que ele deixa de ser uma ação desconhecida. É ela que está vivenciando a experiência e só ela tem condições de dizer qual é a maneira que Ihe traz menos desconforto.

Sentimentos Externados - Nas entrevistas com as crianças, foi grande o número de depoimentos em que elas externaram seus sentimentos em relação à internação e à vários fatores a ela relacionados.

Durante o processo de cuidado, desenvolvido no decorrer da hospitalização, o número de intervenções dos cuidadores junto à criança é incontável. São procedimentos, exames, aferições, que se repetem e alternam na rotina diária da criança hospitalizada. Mesmo que os cuidadores empenhem-se em conversar com a criança, explicando-Ihe todas as ações direcionadas a ela, sempre persistirá o medo do desconhecido, natural em qualquer individuo e evidenciado neste depoimento:

Eu achei que seria até mais dificil quando fui colocar o soro (Vitor, 11 anos). 
Um dos maiores temores, demonstrado pelas crianças, sem dúvida é o medo da dor. Em suas falas fazem várias referências a este assunto, sobretudo a dor nas punções venosas. Demonstram participação como agentes ativos do próprio cuidado, expressando opiniōes junto aos cuidadores, principalmente quando mão gostam da intervenção.

Eu não gosto quando me picam (Joana, 7 anos).

Eu peço prá eles fazerem o possivel prá não me picarem (Vanessa, 12 anos).

Este "fazer o possivel", dentro do contexto da entrevista, significava para a criança investir em tentativas para a manutenção de uma veia posicional, ainda que esta apresenta-se um fluxo menor do que o esperado.

A respeito da reação das crianças à dor, $M o t t a(1988$, p. 168) afirma que "as crianças ao serem submetidas a procedimentos dolorosos ( punção venosa, curativos, sondagens, e outros), muitas vezes entram em pânico, gerando muita ansiedade nos pais". A mesma autora fazendo referência a permanência dos pais junto ao filho doente, afirma que esta "tem como finalidade diminuir a ansiedade da criança, facilitar a adaptação ao hospital, reforçar e/ou favorecer os vínculos afetivos entre os pais e filhos..."(p. 169).

"Ter medo, sentir-se sozinha na ausência dos pais, pode fazer aflorar, na criança, a fantasia de abandono ou punição por algo errado que tenha feito" (Ribeiro, 1991, p. 265).

Nos depoimentos colhidos com as crianças, fica claro o sentimento de solidão que as invade na ausência dos pais, ainda que permaneçam acompanhadas de outro cuidador.

Quando a mãe sai elas me cuidam. Ontem eu chorei porque a mãe saiu (Joana, 7 anos).

Gonzaga e Arruda (1998, p. 199) vão ainda mais longe, afirmando que "a permanência de um dos pais ou familiares como acompanhante, possibilita que sejam minimizadas as consequências da doença e da hospitalização das crianças e adolescentes..." Além disso, no Estatuto da Criança e do Adolescente é assegurado o direito destes a presença de seus pais durante a hospitalização (BRASIL, 1990).

Entretanto, ainda que os cuidadores e a presença da equipe de saúde não substituam a figura dos pais, a criança manifesta um sentimento de segurança e proteção quando percebese acompanhada por eles.

Ela cuida. Vem me olhar de vez em quando (Joana, 7 anos).

Por outro lado, valorizar este sentimento da criança e demonstrar a ela que estamos sempre disponiveis é de grande importância para a integração com a criança e a familia, e para o sucesso de nossas ações de cuidado. "A disponibilidade refere-se ao tempo que a enfermeira deve dispor para o paciente, o que nem sempre é possivel dado as condiçōes de trabalho a ela impostas" (Crossetti; Arruda; Waldow, 1998, p. 161). As autoras afirmam que os profissionais muitas vezes atuam em condiçōes insalubres, acabando por executar ações de não cuidado.

Além de valorizarem a permanência dos cuidadores as crianças demonstram também valorizar a disponibilidade demonstrada nestes contatos, sentem-se importantes para o profissional quando têm sua presença sem precisar solicitá-la.

Ela vem sempre me olhar e não precisa ligar a luzinha (sinalizador de chamada dos quartos) (Joana, 7 anos).

A presença e permanência dos cuidadores é, sem dúvida, importante em qualquer circunstância, entretanto, estas açōes de cuidado tomam grande proporção frente ao sentimento de restriçäo, fortemente manifestado pelas crianças.

Sentem-se restritas no seu "ir e vir ", em função de algumas patologias que estabelecem limitação de movimentos. A terapêutica muitas vezes também lhes reduz o poder de movimentação dentro do ambiente hospitalar.

Eu queria que a mãe deixass eu caminhar prá pegar as coisas (Régis, 9 anos).

Eu não gosto é quando elas colocam o soro, porque eu queria brincar (Nádia, 10 anos).

Gonzaga e Arruda (1998, p. 206) afirmam que "este sofrimento pode ser minimizado pelo cuidador não só pela orientação ao paciente mas também pelo apoio, pelo afeto..." 
As crianças demostram também um sentimento de restrição do tempo disponivel para suas atividades diárias de estudo e lazer, relatando as adaptações que fazem para adequar seu cotidiano à rotina hospitalar e à terapêutica.

Ás vezes estudo um pouquinho num dia, às vezes faço o resto no outro dia, das coisas que eu preciso fazer (Milena, 12 anos).

Diante de uma realidade tão serceadora quanto a do universo hospitalar, a criança organiza suas respostas comportamentais em duas direções divergentes, manifestando um sentimento de conformismo ou interagindo de maneira mais positiva com o ambiente, possibilitando um sentimento de liberdade.

Segundo Gonzaga e Arruda (1998), a criança aceita com dificuldade as restrições. As autoras caracterizam suas reações como de passividade ou agressividade.

Em algumas situações as crianças demonstram conhecimento acerca de restrições ocosionadas pela doença, e aceitam de maneira tranquila estes fatos. Mantém seu comportamento dentro dos limites impostos por estas restrições. A maioria das crianças submetem-se aos procedimentos, aparelhos e horários, mesmo preferindo outras atividades, como passeios e brincadeiras. Algumas vezes chegam a sugerir métodos alternativos recuperação de dispositivo de infusão através de troca do curativo - mas caso năo consigam um resultado positivo submetem-se aos procedimentos.

Eu só queria ir na recreação lá do oitavo andar... se tiver alguém indo com cepácea ${ }^{4}$ daí não dá prá ir (Milena, 12 anos).

Mas as vezes não dá né. Eu tenho uma bombinha (bomba de infusão) e fico presa nela (Vanessa, 12 anos).

Se não resolve, dai a gente é picada do mesmo jeito (Vanessa, 12 anos).

Morse (1998, p. 83) classifica este comportamento de conformismo como "submissão ao cuidado". Diz que existem diferentes niveis e tipos de submissão e que o mais comumente observado em crianças é a submissão condicional, onde ocorre uma relação de negociação entre paciente e enfermeiro, na qual o primeiro solicita informaçöes sobre o procedimento, por vezes exigindo muitos detalhes. Quando suas solicitações são atendidas "sentem-se seguros, acreditam na equipe, sentem-se sob controle e se submetem ao cuidado."

Por outro lado, experimentam um sentimento de liberdade quando têm a possibilidade de opinar e organizar suas atividades diárias. "Liberdade é um sentimento, uma sensação que a pessoa tem em termos de sua habilidade e possibilidade de fazer as coisas que deseja, sentir que tem habilidade para controlar seus assuntos e tomar decisões sobre o que é necessário fazer, mesmo que este algo Ihe desagrade; exercer controle sobre a própria vida; sentir-se livre: ter liberdade de ir e vir" (Morse, 1998, p. 97).

Mas é tudo livre. Se quiser ir na recreação vai. Se não quiser não vai. É assim, bem livre (Vanessa, 12 anos).

Experimentam o sentimento de liberdade quando podem usufruir do tempo vago realizando atividades prazerosas como passear, brincar, ir à escola. É comum entre as crianças internadas, portadoras de patologias crônicas a saida da unidade de internação, em horários oportunos, de maneira que não prejudique a terapêutica em andamento. Estas saidas são utilizadas para que a criança continue frequentando a escola, para passeios em familia, passeios em casa, ou para simplesmente brincar nos arredores do hospital ou em parques próximos.

Eu gosto de sair, depois voltar quando tem medicação (Aline, 9 anos).

É oportuno ressaltar a importância do ato de brincar no mundo da criança. Para Motta (1988, p. 171), "O brinquedo é um fator importante no desenvolvimento da criança, pois, através dele ela elabora os seus sentimentos. Considerando que durante a hospitalização a criança

${ }^{4}$ Cepácea: Burkolderia Cepácea, bactéria mais resistente que a Pseudomonas aeruginosa a antibióticos, e a resistência desenvolve-se mais rapidamente(Damaceno e Carvalho, 1996, p. 22). 
esta exposta a uma série de situações novas e, por vezes, adversas, o brinquedo passa a ter um grande significado, uma vez que auxilia na sua adaptação"

$E$, finalmente, as crianças expressam sentimentos de liberdade quando conseguem elaborar estratégias para adaptar sua rotina diária (lazer, escola, etc...) à terapêutica.

"Tem um suporte (do soro), dai minha mãe me leva prá lá e prá cá. Ou fico no quarto e minha mãe tem joguinhos lá. Dai, nós brincamos com os joguinhos" (Nádia, 10 anos).

Segundo Morse (1998, p. 101), "a pessoa que experiencia liberdade consegue exercer controle sob sua própria vida nas suas relações com o ambiente, mesmo que lhe pareça ser desagradável".

Algumas crianças manifestam insatisfaçäo relacionada à alimentação oferecida no hospital, à rotina diária na unidade e ao ambiente de recreação.

Ah! Eu mudaria a comida! A comida do hospital é muito ruim! (Vanessa, 12anos).

Mando elas mudarem a medicação prás horas que eu não fosse sair (Joana, 7 anos).

A única coisa que eu gostaria que tivesse no hospital é uma outra sala de recreação. Não só pra criança ou adulto. Doze, treze anos não é adulto ainda... (Vitor, 11 anos).

Estas verbalizaçōes reivindicam mudanças na rotina diária da unidade de maneira que consigam manter suas preferencias pessoais, atividades escolares e de lazer.

Caracterizando o Cuidado - Durante as entrevistas as crianças identificaram o cuidado recebido referindo-se às caracteristicas dos cuidadores e definindo o que é "cuidar bem" e, pelo contrário, o que é "cuidar mal". Apontaram também aspectos positivos e negativos encontrados no cotidiano da unidade de internação hospitalar.

Ao caracterizarem os cuidadores referem-se principalmente à equipe de enfermagem. São unânimes em exprimir sua satisfação em relação ao processo de cuidado desenvolvido durante a internação, repetindo várias vezes expressões como: "legais", "alegres", "queridas" e "carinho" entre outras. As falas abaixo caracterizam esta afirmação:

Elas são boas, são queridas (Joana, 7 anos).

Eu acho elas legais, queridas. Todo mundo é amigo! (Milena, 12 anos).

Elas são legais... têm alegria, dão mais alegria prá gente (Nádia, 10 anos).

A demonstração de comportamentos positivos e alegres por parte dos cuidadores, onde estejam incluidos brincadeiras e expressões divertidas impulsiona a criança a uma convivência mais harmoniosa e agradável. Isto se dá porque a criança frequentemente é influenciada por aqueles que a cercam, modelando seu comportamento conforme o que percebe no ambiente ao seu redor.

...elas são legais... têm carinho! ...brincam comigo (Régis, 9 anos).

A criança valoriza o cuidado que é realizado com carinho. Quando este cuidado vem acrescido de brincadeiras e é realizado no ambiente em que a criança se encontra, em meio a seus brinquedos, transmite-lhe segurança e faz com que ela se sinta mais próxima do cuidador.

A maioria tem bastante paciência, cuidam bem de mim. Elas gostam do trabalho. Dá prá ver no jeito delas, săo alegres (Vitor, 11 anos).

A criança percebe quando o cuidador demonstra prazer ao desenvolver suas atividades, reconhece quando o cuidado ultrapassa as barreiras do formal, quando não è apenas o cumprimento de uma tarefa. "Ser bem tratado, cuidado e ser amado pelas pessoas do hospital, pai, mãe, visitas, companheiros de quarto, representa para o cliente um sentimento de satisfação em relação ao cuidado, que por sua vez Ihe proporciona alegria e contentamento" (Gonzaga; Arruda, 1998, p. 202)

As crianças definem "cuidar bem" como o cuidado que é feito com carinho, competência e sincronizado com suas necessidades. Respondem às questōes que focalizam o comportamento do cuidador relacionado ao "cuidar bem", com afirmações do tipo:

Dando carinho e também fazendo as coisas com cuidado (Aline, 9 anos).

Quando fazem o furinho forte no dedo, é prá não ter de fazer de novo (Aline, 9 anos). 
Tem de ser carinhosa e saber a hora de fazer o remédio (Milena, 12 anos).

Relacionam o "cuidar mal" ao tratamento rispido ou relapso e à falta de disponibilidade por parte dos cuidadores.

Cuidar mal é xingar. Fazer coisas erradas. Não fazer nada prá mim (Aline, 9 anos).

Umas esquecem a coisa (solução de heparina) prá tirar o soro (Joana, 7 anos).

Citam como aspectos positivos, encontrados na internação hospitalar, a utilização de materiais que minimizem a restrição imposta pela terapêutica utilizada, bem como a manutenção de suas atividades escolares e de lazer.

Poder ficar fora do soro, só com a borrachinha (plug adaptador). . ...ir prá escolinha, prá recreação (Joana, 7 anos).

A utilização do plug adaptador permite que o acesso venoso seja heparinizado, substituindo a permanência de um soro de manutenção, liberando a criança para deslocar-se dentro do ambiente de internação ou mesmo fora dele, em passeios mais longos.

Citam como um dos aspectos negativos da internação a necessidade de interrupção de suas atividades.

Eu saio prá passear e dai as médicas vem me olhar. Tem que parar o passeio e voltar (Joana, 7 anos).

Outros aspectos negativos apontados são os procedimentos dolorosos; a privação da alimentação, em função de alguns exames que exijam jejum; e o sabor da alimentação oferecida pelo hospital. anos).

Não gosto quando eles me picam. Também não gosto de ficar em jejum (Joana, 7

A comida do hospital é muito ruim (Vanessa, 12 anos).

Percepções Acerca do Tempo - Nos depoimentos das crianças são encontradas frequentemente referências ao tempo que aguardam, seja pela realização de exames e procedimentos, ou quando precisam ficar restritas, durante a infusão de medicamentos. Relacionam o cuidado adequado e de qualidade ao fato de receberem as medicações no horário certo.

Vanessa que tem experiência em outra instituição hospitalar, faz comparação entre elas.

Ah! Lá (outro hospital) não cuidavam bem da gente. Davam medicações em horas alteradas. Assim, no caso, a medicação era às $4 h$, davam às 4 h30min ou $5 h$. Ah! Coisa chata de se ver. Aqui não. Chega 4 h, ou até pode passar um pouquinho, mas eles estão ali prá dar a medicação. Aqui é legal (Vanessa, 12 anos).

Entretanto, nem todas as crianças reconhecem nos procedimentos realizados a existência deste cuidado qualificado.

Queria que eles acertassem o relógio... sempre estão 5 min atrasados (Luan, 9 anos).

Segundo Morse (1998, p. 75), "do ponto de vista do paciente, a obtenção de conforto inclui a habilidade de confiar; ser apoiado; ter esperança; receber um cuidado competente, bem dosado e sincronizado."

O fato de precisarem aguardar a realização de exames ou o periodo de infusão de medicações é identificado pelas crianças como fonte de desconforto.

Outra coisa que eu queria é que lá em baixo (áreas de exames ambulatoriais), quando a gente vai fazer um exame, tivesse uma área separada prá quem tá internado. Prá gente não ficar esperando aqui em cima (Vitor, 11 anos).

Essa ai (medicação) é muito chata porque é lenta, lenta! (Joana, 7 anos).

Frequentemente oferecemos o conforto em resposta a uma manifestação de sofrimento ou necessidade do paciente. Estas manifestações podem ocorrer na forma de "uma resposta à dor, inquietação, um sinal de sofrimento, uma declaração, expressão ou até mesmo uma solicitação" (Morse, 1998, p. 74).

As crianças sentem-se desconfortáveis também com a falta de disponibilidade, 
demonstrada por alguns cuidadores.

Ah! Tudo prá mim é ótimo do jeito que eles tratam a gente, eu só queria que eles viessem um pouquinho mais rápido quando a gente chama! (Régis, 9 anos).

Tem umas que quando a gente liga a luzinha demoram um século (Joana, 7 anos).

A dúvida de que suas necessidades podem ou não ser atendidas assim que são manifestadas, faz com que as crianças sintam-se inseguras e desconfortáveis, sem controle da situação a qual foram submetidas pela hospitalização.

"Tempo é uma dimensão importante para ambos os conceitos - conforto e desconforto." Ele proporciona à criança um referencial para a construção de mecanismos que the auxiliem no controle da situação que está vivenciando. (Arruda; Nunes, 1998, p. 105-106).

\section{CONSIDERAÇÕES FINAIS}

Este estudo foi realizado buscando identificar as percepções da criança sobre o cuidado que recebe durante a hospitalização, e sobre as ações de cuidado nela envolvidas. Busquei também verificar como a criança identifica os cuidadores e como os caracteriza.

Ao analisar os dados obtidos junto às crianças, relacionando-os à literatura, constatei diversos fatores que ilustram a realidade da unidade de internação onde a pesquisa foi desenvolvida.

A hospitalização de uma criança é sempre uma situação delicada, geradora de stress para ela e para sua familia.

O cuidado adequado, humanizado e eficiente, que enxergue na criança um ser social, pertencente a uma realidade distante e diversa daquela observada na unidade de internação, é indispensável para que seja minimizado o impacto desta situação sobre o desenvolvimento infantil.

A manutenção do vinculo familiar torna a criança mais segura e confiante diante das ações de cuidado, que muitas vezes podem ser encaradas por ela como agressões. A equipe de saúde deve procurar engajar a família e a própria criança em seu cuidado, estimulando-os a continuarem desenvolvendo atividades da rotina diária, como fornecer alimentação à criança e realizar sua higiene, atuando assim como agentes ativos no processo de cuidado em andamento.

Outro ponto importante a ser ressaltado diz respeito ao estimulo para a manutenção das atividades normais da criança. Sempre que possivel atividades de lazer e estudos devem ser respeitados no dia a dia da internação pediátrica.

A criança deve ser auxiliada a enfrentar a realidade, por vezes adversa, da unidade de internação; auxiliada a lidar com o medo do desconhecido e a expressar e elaborar a dor e a solidão que sente. Os procedimentos realizados com a criança devem ser sempre previamente explicados, e reações normais de choro ou verbalizações de medo não devem ser sufocadas, mas acolhidas com demonstrações de compreensão.

É de extrema importância a valorização das opiniões e sugestões da criança quanto à satisfação de suas necessidades ou à realização de ações de cuidado. Desta maneira ela conseguirá interagir com o ambiente e com os cuidadores, criando estratégias que the possibilitarão um certo controle sobre si mesma e sobre a realidade que a cerca.

Mostrar-se disponivel e atento às necessidades da criança proporciona-Ihe conforto e apoio, possibilitando que vivencie o momento da hospitalização da maneira menos traumática possivel.

Embora as crianças evidenciem em seus depoimentos necessidades ainda não atendidas durante a internação, deixam claro sua satisfação frente ao cuidado desenvolvido pela equipe de saúde. Mostram-se atuantes e integradas, assim como suas familias, no processo de cuidado.

ABSTRACT: This is an exploratory qualitative study carried out in a hospital-school in Porto Alegre. Its 
purpose is to identify children's perception concerning the care received during hospitalization. Eight children, from six to twelve years of age participated in this investigation, after each person responsible for the child signed a consent form. Data was collected in the in-patient unit through in-depth interviews. Five different themes emerged from the analysis of the interviews: identification of the caretakers; children's perception of care; expression of inner feelings, description of the care received and the caretakers and perception of time. The study shows that hospitalization generates stress for the child and its family. Health care which is more appropriate and efficient minimizes the impact of hospitalization and should include the following aspects: family's and child's commitment to self-care, maintenance of family bonds and of regular activities, previous explanation of procedures to be performed respect for the child's opinions and suggestions, nursing team's availability and attention to the child's needs.

KEYWORDS: care, pediatric hospitalization, children's perceptions

RESUMEN- Estudio cualitativo exploratorio realizado en un hospital escuela de Porto Alegre con el fin de identificar las percepciones de los niños sobre el cuidado durante la hospitalización. Participaron ocho niños de seis a doce años, con la autorización del responsable, mediante la firma de consentimiento informado. Se colectaron los datos en la unidad de internación, con entrevistas direccionadas. Analizando las respuestas surgieron cinco temas: Identificando los cuidadores; Percepciones del Niño Respecto al Cuidado; Sentimientos Expresados; Caracterizando el Cuidado y los Cuidadores; Percepciones Sobre el Tiempo. Quedó evidenciado que la hospitalización genera estrés al niño y a la familia. Un cuidado adecuado, humanizado y eficaz minimiza el impacto de la hospitalización. En ese cuidado están implícitos: inserción de la familia y del niño en el cuidado, manutención del vínculo familiar y de sus actividades normales, explicación previa de los procedimientos que serán realizados, valorización de las opiniones y sugerencias del niño, disponibilidad y atención del equipo para que atiendan a sus necesidades.

PALABRAS CLAVE: cuidado, hospitalización infantil, percepciones del niño

\section{REFERÊNCIA BIBLIOGRÁFICA}

ARRUDA, Eloita Neves; NUNES, Ana Maria Pereira. Conforto em Enfermagem: uma análise teóricoconceitual. Revista Texto e Contexto-Enfermagem, v. 7, n. 2, p. $93-110,1998$.

BRASIL. Estatuto da Criança e do Adolescente. Ministério da Ação Social/ Centro Brasileiro para a Infância e Adolescência, 1990.

CARVALHO, Paulo Roberto Antonacci. A assistência, o ensino e a pesquisa na pediatria hospitalar. I $n$

CECCIM, Ricardo Burg. Criança hospitalizada - Atenção Integral como Escuta à Vida. 1, ed. RS Editora da Universidade / UFRGS, 1997.

CECCIM, Ricardo Burg; CARVALHO, Paulo R. Antonacci. Criança hospitalizada - atenção integral como escuta à vida. 1. ed. Porto Alegre: Editora da Universidade / UFRGS, 1997.

CROSSETTI, Maria da Graça Oliveira; ARRUDA, Eloita Neves; WALDOW, Vera Regina. Elementos do cúidar / cuidado na perspectiva de enfermeiros de um municipio gaúcho. Revista Texto e Contexto - Enfermagem, v. 7, n. 2, p. $151-173,1998$

ERDMANN, Alacoque Lorenzini. O sistema de cuidados de enfermagem: sua organização nas instituiçöes de saúde. Revista Texto e Contexto-Enfermagem, v. 7, n. 2, p. 52 - 69, 1998

GOMES, Romeu. A análise de dados em pesquisa qualitativa. In: MINAYO, Maria Cecilia de Souza. 
(Org.). Pesquisa Social - Teoria, método e criatividade. 12. ed. Petrópolis, RJ: Vozes, 1999.

GONZAGA, Maria Lủcia de Carvalho; ARRUDA, Eloita Neves. O cuidado na hospitalizaçāo: uma perspectiva infanto-juvenil. Revista Texto e Contexto-Enfermagem, v. 7, n. 2, p. 195-218, 1998.

MORSE, Janice M. A enfermagem como conforto: um novo enfoque do cuidado profissional. Revista Texto e Contexto-Enfermagem, v. 7, n. 2, p. $70-92,1998$.

MOTTA, Maria da Graça Corso da. O desenvolvimento da criança $\theta$ as alterações decorrentes da hospitalização. Porto Alegre, 1988. Dissertação (Mestrado) - Curso de Pós-graduação em Educação, Universidade Federal do Rio Grande do Sul.

POLIT, Denise F.; HUNGLER, Bernardette P. Fundamentos de pesquisa em enfermagem. 3 , ed. Porto Alegre: Artes Mẻdicas, 1995.

RIBEIRO, Nair Regina Ritter. A experiência da criança em Unidade de Terapia Intensiva: subsidios para a prática e o ensino de enfermagem. Porto Alegre, 1991. Dissertação (Mestrado) - Curso de Pós-graduação em Educação - PUC-RS

RIBEIRO, Nair Regina Ritter. Familias vivenciando o risco de vida do filho. Florianópolis, 1999. Tese (Doutorado em Enfermagem) - Curso de Pós-graduação em Enfermagem, Universidade Federal de Santa Catarina.

WALDOW, Vera Regina. Cuidado humano: o resgate necessário. Porto Alegre: Sagra Luzatto, 1998.

WONG, Donna L., Enfermagem Pediátrica. Elementos essenciais à internação efetiva. 5. ed. RJ: Guanabara Koogan, 1999 